\title{
Optimization of DC-Magnetron Sputtered Molybdenum (Mo) thin Film Electrodes for Electrodeposited CZTS Solar Cells
}

Haribhau Borate ${ }^{1}$, Avinash Rokade ${ }^{1}$, Subhash Pandharkar ${ }^{1}$, Ravindra Waykar ${ }^{1}$, Bharat Gabhale ${ }^{1}$, Ajinkya Bhorde ${ }^{1}$, Rahul Aher ${ }^{1}$, Shruthi Nair ${ }^{1}$, Priti Vairale ${ }^{1}$ and Sandesh Jadkar ${ }^{2 *}$

In present work, we have prepared molybdenum (Mo) thin films having low resistivity and good adhesion to corning substrates by using DCmagnetron sputtering. The influence of working gas pressure on electrical, structural, morphological, optical and topological properties of Mo thin films have been investigated using various techniques such as Hall Effect measurement, x-ray diffraction (XRD), field emission scanning electron microscopy (FE-SEM), UV-Visible spectroscopy, non-contact-atomic force microscopy (NC-AFM) etc. Hall Effect measurements showed that the electrical resistivity of Mo films increases with increase in working gas pressure. The enhancement in adhesion of Mo with increase in working gas pressure was observed by Cross-hatch cut and Scotch tape adhesion test. As-deposited Mo films showed preferred orientation in (110) direction and decrease in crystallite size with increase in working gas pressure. It also showed that the Mo films deposited at 0.01 mbar exhibit compressive strain while those deposited at 0.05 mbar and above exhibit tensile strain. FE-SEM analysis showed that all Mo films have dense, homogeneous and crack-free microstructures. NC-AFM characterization showed that surface roughness of films increases with increase in working gas pressure. The as-synthesized Mo thin films were then successfully used to deposit $\mathrm{Cu}_{2} \mathrm{ZnSnS}_{4}(\mathrm{CZTS})$ layer by electrochemical deposition. Kesterite-CZTS thin films with preferred orientation along (112) direction were synthesized at room temperature by single step method through electrodeposition-annealing route.

Keywords: Molybdenum; DC sputtering; AFM; XRD; CZTS

Received 28 December 2018, Accepted 28 January 2018

DOI: $10.30919 / \mathrm{esmm} 5 \mathrm{f} 202$

\section{Introduction}

Due to industrialization and ever-growing world's population, there is huge demand of energy. Currently, the energy demand is fulfilled by fossil fuels. However, burning of fossil fuel produces greenhouse gases, which contributes to global warming. Nowadays, photovoltaics (PV) turn out to be a more essential technology to solve the newly emerged problems related to environment like global warming. The PV system converts sunlight directly into electrical energy and provides pollution free power. As -on-today the PV market is dominated by silicon ( $\mathrm{Si}$ ) wafer based solar cells. However, due to high production cost, there is limitation on the application of Si based solar cells in domestic and industrial sectors. The dilemma of high cost of elements can be solved by deposition of semiconductor thin film on the substrate instead of using Si wafer. ${ }^{1}$ The major advantage of thin film solar cells is that their band gap of can be adjusted by varying the composition of elements. ${ }^{2}$ Consequently, larger portion of solar spectrum can be used to achieve higher efficient solar cells. Hence, from last few years, silicon based solar cells are replaced by chalcogenide thin film solar cells such as copper indium gallium sulphide/selenide (CIGS) and copper indium sulphide/selenide (CIS), etc. The CIGS solar cells have reached the

${ }^{\prime}$ School of Energy Studies, Savitribai Phule Pune University, Pune 411 007 (India)

${ }^{2}$ Department of Physics, Savitribai Phule Pune University, Pune 411 007 (India)

*E-mail: sandesh@physics.unipune.ac.in power conversion efficiencies up to $20.8 \%$. $^{3}$ This efficiency is comparable with the $25 \%$ record efficiency of crystalline silicon solar cells. ${ }^{4}$ However, there are limitations on application of CIGS and CIS solar cells due to scarcity of key elements and their toxic problems concerned with health and safety. ${ }^{5}$ Hence, many efforts have been made in worldwide to develop non-toxic and low cost thin film solar cell by abundant materials from earth crust. Recently, quaternary compound semiconductor, $\mathrm{Cu}_{2} \mathrm{ZnSnS}_{4}$ (CZTS) has been receiving huge consideration due to their excellent photovoltaic and optoelectronic properties. ${ }^{6,7}$ The CZTS is the promising candidate material because of their low cost, earth abundant and non-toxic elements. Moreover, it has optimal band gap of the order of 1.4-1.5 eV with high absorption coefficient $10^{4} \mathrm{~cm}^{-18,9}$ Theoretical efficiency of CZTS thin film solar cell is $32.4 \%{ }^{10}$ Recently, the power conversion efficiency of $12.6 \%$ has been achieved by Mitzi et al. ${ }^{11}$

The metal back contact collects the charge carriers from absorber layer to achieve better current density, which enhances the efficiency of the solar cell. ${ }^{12}$ The great varieties of material were studied as the metal back contact for solar cells, including silver $(\mathrm{Ag})$, gold $(\mathrm{Au})$, aluminum $(\mathrm{Al})^{13}$, molybdenum (Mo), platinum $(\mathrm{Pt}){ }^{14}$ tungsten $(\mathrm{W})$, tantalum $(\mathrm{Ta})$, niobium $(\mathrm{Nb})$, vanadium $(\mathrm{V})$, titanium $(\mathrm{Ti})$, magnesium $(\mathrm{Mn}),{ }^{15}$ nickel $(\mathrm{Ni})^{16}$ etc. Among them, molybdenum is the best back contact material for thin film solar cells. ${ }^{17}$ Mo possesses properties such as chemical inertness, high conductivity, ${ }^{18}$ suitable ohmic contacts for chalcopyrite compounds based solar cells, ${ }^{19}$ relative stability at the processing temperature and resistance to alloying with $\mathrm{Cu}, \mathrm{Zn}$ and $\mathrm{Sn}^{20}$ All these properties of Mo satisfy the necessary requirements of best back contact material for the chalcopyrite compounds based solar cells. The Mo thin 
films can be fabricated by variety of techniques such as radio frequency (RF) magnetron sputtering, ${ }^{21}$ e-beam evaporation, direct current (DC) magnetron sputtering, ${ }^{22}$ etc. However, DC magnetron sputtering is the suitable technique since it provides better adhesion, good uniformity and scalability over large areas of substrate. ${ }^{23}$ It is reported that the properties of DC magnetron sputtered thin films depend on the sputtering parameters such as substrate temperature, target-to-substrate distance, deposition power, working gas pressure, etc. The influence of sputtering parameters on properties of Mo thin films has been studied by many research groups. Rondiya et $a l^{24}$ studied the effect of substrate temperature on DC sputtered Mo thin films and reported that surface roughness of the film increases as the substrate temperature increases. The smoother Mo films with high resistivity can be fabricated at higher target-to-substrate distance has been reported by Pandharkar et al. ${ }^{25}$. Moreover, Guo et al. ${ }^{26}$ fabricated the Mo thin films with good adhesion with substrate by DC and RF magnetron sputtering at low deposition power and reported that the electrical resistivity of Mo thin film decreases with increase in deposition power.

The adhesion and residual stress plays a crucial role in the performance of the thin film solar cells. ${ }^{27}$ Malhotra et al. ${ }^{28}$ Reported that excessive residual stress during growth of Mo thin film can affect their electrical, mechanical and optical properties. The Mo thin films with compressive stress have low resistivity but poor adhesion to the substrate and those under tensile stress have high resistivity and good adhesion to substrate. ${ }^{29}$ Deambrosis et al..$^{30}$ predicted that change in stress in the films is due to the variation of deposition rate. Moreover, the change in working gas pressure influences the deposition rate and mean free path of the sputtered atoms. ${ }^{31}$ A recent study revealed that increasing argon pressure during Mo thin film deposition increases the width of amorphous oxidized phase $\left(\mathrm{MoO}_{3}\right)$ at inter-grain regions that acts as a channel for sodium diffusion into the absorber layer. ${ }^{32}$ As a back contact in thin film solar cells, lower electrical resistivity and good adhesion with the substrate are essential to get highly efficient solar cells. ${ }^{33}$ Scofield et al. ${ }^{17}$ showed that adhesive films with low resistivity can be fabricated by varying working gas pressure. In the present research work, we have investigated the effect of working gas pressure on adhesive, structural, optical, morphology and electrical properties of Mo thin films to achieve better sputtering conditions. Furthermore, the performance of the fabricated Mo thin film with better property, were studied by using it as a working electrode in electrochemical deposition of CZTS thin films.

\section{Experimental}

\subsection{Synthesis of Mo thin films}

The molybdenum (Mo) thin film fabrication was carried by commercial planar DC magnetron sputtering unit (Model: 12" MSPT, Hind High Vacuum) using a target of 4 inch diameter (99.99\%, Vin Karola Instrument, USA) on corning \#7059 substrate $(2 \mathrm{~cm} \times 5 \mathrm{~cm})$. The following cleaning procedure of substrate was used for Mo thin film deposition. First, substrates were cleaned using soap and piranha solution and next by double distilled water with ultrasonic bath for 30 min. After drying, well cleaned substrates were mounted on substrate holder in the vacuum chamber. The target-to-substrate distance and substrate temperature were maintained at $90 \mathrm{~mm}$ and $400{ }^{\circ} \mathrm{C}$ respectively. The deposition process was carried out for 40 minutes. After achieving a base pressure of $2 \times 10^{-5}$ mbar, pure Ar (99.99\%) was introduced in the vacuum chamber. Depositions were performed at different working gas pressures from $0.01 \mathrm{mbar}$ to $0.1 \mathrm{mbar}$ in steps of $0.05 \mathrm{mbar}$. The deposition parameters are listed in the Table 1 .

\subsection{Film characterization}

The structure and crystallinity of sputtered Mo thin films was investigated by using a x-ray diffractometer (Bruker D8 Advance, Germany) utilizing the $\mathrm{CuK}$ line $(\lambda=1.54 \AA)$. The surface morphological evaluation of Mo thin films was analyzed by using field emission scanning electron microscope (FE-SEM) (Hitachi, S-4800, Japan) with the operating voltage of $15 \mathrm{kV}$. The thickness measurement of deposited Mo thin films was estimated by using cross sectional SEM (JEOL JSM-6360A) with operating voltage of $20 \mathrm{kV}$. The surface topographical investigation was carried out by using non-contact mode atomic force microscopy (NC-AFM) (JEOL, JSPM-5200). The reflection spectra were measured by using a UV-Visible spectrophotometer (JASCO, V-670) in the range of 400-800 nm. The electrical resistivity of Mo thin films was estimated by using Ecopia Hall Effect measurement (HMS-3000) set up. The Mo film thickness was calculated by surface profiler (KLA Tencor, P-16+) and also verified by FE-SEM analysis.

\section{Results and Discussion}

\subsection{Adhesion test of Mo thin films}

The adhesion test of Mo thin films was carried out by Cross-hatch cut and Scotch tape test. The film deposited at low working gas pressure

Table 1 Deposition parameters used to synthesize Mo thin films by using DC-Magnetron sputtering.

\begin{tabular}{lll}
\hline Deposition parameter & Parameter value & Unit \\
\hline Substrate temperature & 400 & ${ }^{\circ} \mathrm{C}$ \\
Target -to-substrate distance & 9 & $\mathrm{~cm}$ \\
Deposition time & 40 & min \\
Base pressure & $2 \times 10^{-5}$ & mbar \\
Deposition power & 200 & Watt \\
Working gas pressure & $\mathbf{0 . 0 1 - 0 . 1}$ & mbar \\
\hline
\end{tabular}


(0.01 mbar) shows poor adhesion and gets delaminated during tape test while, those deposited at higher working gas pressure $(0.05$ mbar and above) shows good adhesion. Moreover, the enhancement in adhesion of Mo thin films to the corning glass substrate has been observed when working gas pressure increased from $0.01 \mathrm{mbar}$ to $0.1 \mathrm{mbar}$ (See Table 2).The Mo thin films deposited at lower working gas pressure exhibits compressive strain shown less adhesion while those deposited at higher working gas pressure exhibit tensile strain shown good adhesion. The enhancement in adhesion of Mo thin film with increase in working gas pressure is attributed to transformation of residual stress from compressive to tensile strain. Forest et al. ${ }^{34}$ reported that the compressive stress in thin film is related with the absorption of impurities $(\mathrm{O}, \mathrm{H}$ and water vapor) in the inter-granular voids.

\subsection{Variation of deposition rate}

The deposition rate is calculated from thickness measurement and deposition time period taken for Mo thin film fabrication. The variation of deposition rate as a function of working gas pressure is shown in Fig. 1. It increases from $21.95 \mathrm{~nm} / \mathrm{min}$ to $34.55 \mathrm{~nm} / \mathrm{min}$ when working gas pressure increased from $0.01 \mathrm{mbar}$ to $0.1 \mathrm{mbar}$. The inset table shows the thickness of Mo thin films and the applied working gas pressure. As working gas pressure grows from $0.01 \mathrm{mbar}$ to $0.05 \mathrm{mbar}$, the number of $\mathrm{Ar}$ ions increases, which ejects more number of Mo atoms from target, as a result, deposition rate increases rapidly. While, as the working gas pressure increased further from 0.05 mbar to $0.1 \mathrm{mbar}$, probability of colliding Ar atoms with ejected Mo atoms increases and hence there is a reduction in the kinetic energy of ejected Mo atoms. ${ }^{35}$ As a result, deposition rate increases at a slower rate at higher working gas pressures. It can be predicted that the deposition rate will achieve a saturation value at higher working gas pressures.



Fig. 1 Variation of deposition rate as a function of working gas pressure for Mo films prepared by using DC-Magnetron sputtering.

\subsection{X-ray diffraction analysis}

The x-ray diffraction (XRD) is widely used technique for the study of structural investigation of materials synthesized via different methods. The structural investigations such as crystal structure, preferential orientation of crystal, crystallite size and strain of Mo thin films were investigated from X-ray diffraction (XRD) analysis. The XRD pattern of Mo thin film deposited on corning substrate at various working gas pressures is shown in Fig. 2. The crystallites of Mo thin films have the cubic (BCC) crystal structure (JCPDS card \# 00-001-1208) with preferential orientation along (110) direction. With increase in working gas pressure, the line-width (Full width at half maximum, FWHM) of diffraction plane (110) increases and hence, decrease in its crystallite size $\left(d_{x-\text { ay }}\right)$ is observed. The $d_{x-\text {-ay }}$ was estimated by using Debye-Scherer's formula, ${ }^{36}$

$$
\mathrm{d}_{\mathrm{x}-\mathrm{ay}}=\frac{0.9 \lambda}{\beta \cos \theta_{\mathrm{B}}}
$$

where, $\lambda$ is the wavelength of diffracted radiation, $\theta_{\mathrm{B}}$ is the Bragg angle and $\beta$ is FWHM in radians. It is observed that with increase in working gas pressure the crystallite size decreases (see Table 2). Furthermore, with increase in working gas pressure the diffraction peak (110) slightly shifts towards lower diffraction angle. The shifting of (110) peak position to lower diffraction angle can be attributed to presence of strain in the films. ${ }^{37}$ The intrinsic strain (\%) in the Mo film was calculated from the (110) diffraction peak by using following equation.$^{38}$

$$
\text { Strain }(\%)=\frac{\mathrm{a}-\mathrm{a}_{0}}{\mathrm{a}_{0}} \times 100
$$

where $\mathrm{a}_{0}$ and a represents the reference lattice constant $(0.3143 \mathrm{~nm}$, JCPDS card \# 001-1208) and lattice constant of the Mo films obtained from the XRD measurements respectively.

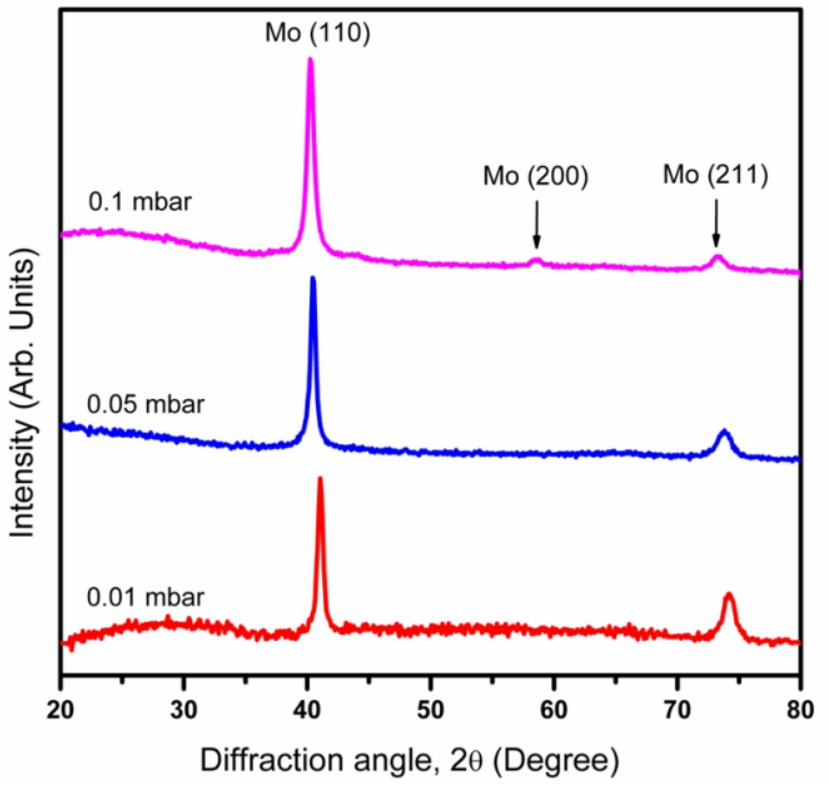

Fig. 2 XRD patterns of Mo films deposited by using DC-Magnetron sputtering at different working gas pressures.

The estimated values of lattice constants and the strain in the DCMagnetron sputtered Mo films are listed in Table 2.

As seen from the Table 2, the Mo films deposited at working gas pressure 0.05 mbar and above exhibit tensile strain and its value increases with increase in working gas pressure, while the Mo film deposited at working gas pressure $0.01 \mathrm{mbar}$ exhibit compressive strain.

\subsection{Field emission scanning electron microscopy (FE-SEM) analysis}

The surface morphological study of Mo thin films has been analyzed by field emission scanning electron microscopy (FE-SEM). Fig. 3(a1)-(a3) shows FE-SEM micrographs of Mo thin films deposited at various working gas pressures. 
Table 2 XRD analysis of Mo films deposited using DC-Magnetron sputtering.

\begin{tabular}{ccccc}
\hline $\begin{array}{c}\text { Working gas pressure } \\
(\mathbf{m b a r})\end{array}$ & $\begin{array}{c}\text { Crystallite size } \\
(\mathbf{n m})\end{array}$ & $\begin{array}{c}\text { Lattice constant } \\
(\mathbf{\AA})\end{array}$ & $\begin{array}{c}\text { Electrical resistivity } \\
(\Omega \mathbf{~ c m})\end{array}$ & $\begin{array}{c}\text { Strain (\%) } \\
\text { Adhesion } \\
\text { tape test }\end{array}$ \\
\hline 0.01 & 16.3 & 3.1075 & $5.67 \times 10^{-5}$ & -1.1291 \\
0.05 & 15.9 & 3.1471 & $2.12 \times 10^{-4}$ & 0.1333 \\
0.1 & 14.5 & 3.1621 & $15.6 \times 10^{-4}$ & 0.6096 \\
\hline
\end{tabular}
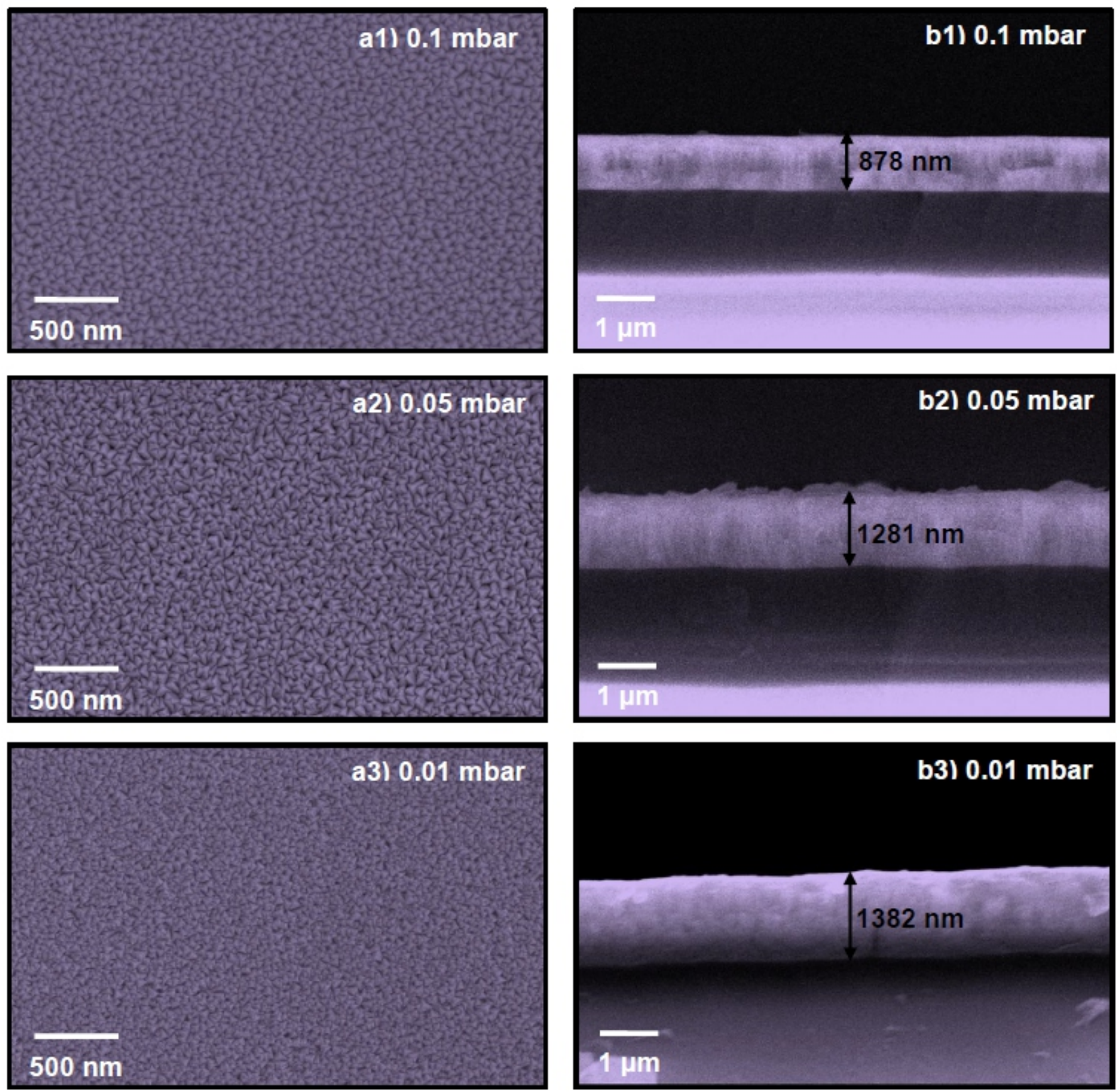

Fig. 3 FE-SEM micrographs of Mo thin films deposited at different working gas pressures a1-a3) Surface morphology and b1-b3) Cross-section view of FE-SEM micrographs. 
As seen from figure, the FE-SEM images clearly show tiny irregular prismatic shape like morphology with decreasing particle size. It is observed that Mo thin film deposited at lower working gas pressure is having dense and homogeneous microstructure without any intergranular voids. Films deposited at higher working gas pressure are less dense and more porous. Hence, enhancement in inter-granular voids and porosity with increase in working gas pressure is observed. At lower working gas pressure due to less particle scattering, Mo atoms with more energy get deposited on the substrate, which forms denser Mo thin film. However, at higher working gas pressure, due to enhanced particle scattering, Mo atoms with reduced energy get deposited on substrate, which forms porous films. ${ }^{38}$ Fig. 3(b1-b3) shows cross-section of SEM micrographs of Mo thin films deposited at various working gas pressures used for the thickness measurements. The thickness measurement evaluated from cross-section SEM micrographs well match with the thickness measured by KLA Tencor, P-16+profilometer.

\subsection{Atomic force microscopy (AFM) analysis}

The surface roughness analysis study of Mo thin film was studied by non-contact atomic force microscopy (NC-AFM). The surface features of deposited Mo films were studied by the measurement of root mean square (RMS) roughness values. Fig. 4 represents the 3-D AFM images of Mo thin films at deposited at various working gas pressures.

As the working gas pressure increased from 0.01 mbar to $0.1 \mathrm{mbar}$, the increase in RMS roughness from $3.32 \mathrm{~nm}$ to $9.78 \mathrm{~nm}$ is clearly observed from figure.

\subsection{UV-Visible spectroscopy analysis}

The efficiency of the thin film solar cell depends on the reflectance of the back contact. For higher reflectance of back contact, more photons get generated, which enhances efficiency of solar cells. ${ }^{39}$ The optical reflection properties of sputtered Mo thin films were recorded using a UV-Visible spectrophotometer. The reflectance of Mo films deposited at various working gas pressures are plotted in Fig. 5 as a function of wavelength.

It is clearly seen from the figure that the enhancement in working gas pressure from 0.01 mbar to 0.05 mbar results into reduction in average reflection of Mo thin film from $\sim 24$ to $\sim 13 \%$ in the visible range. The decrease in average reflection with increase in working gas pressure was observed and this result matches with the reported literature by Cao et al. ${ }^{40}$ The Mo thin films forms denser microstructure at lower working gas pressure, hence shows higher reflectance. However, porosity increases with increase in working gas pressure due to optical scattering. Hence, Mo thin films deposited at higher working gas pressure shows lower reflectance.

\subsection{Electrical resistivity measurement}

The Mo back contact with low electrical resistivity is essential to

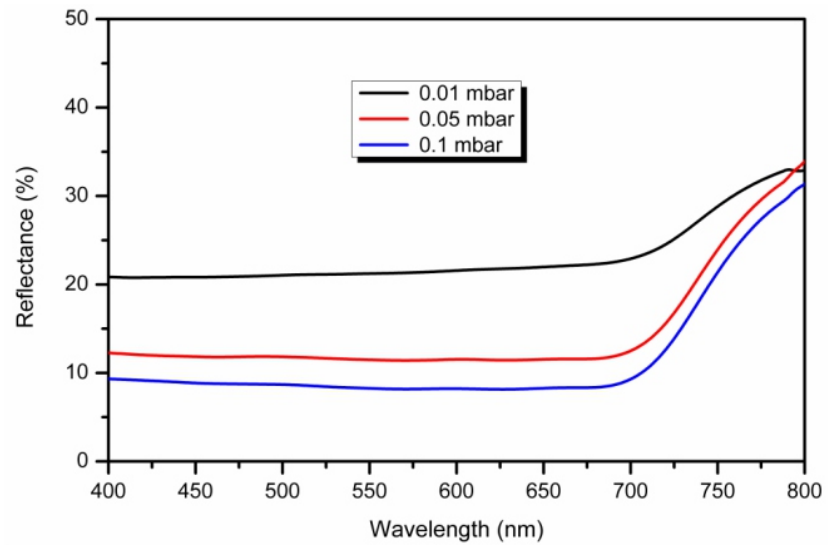

Fig. 5 UV-Visible reflectance spectra of Mo films deposited at different working gas pressures.
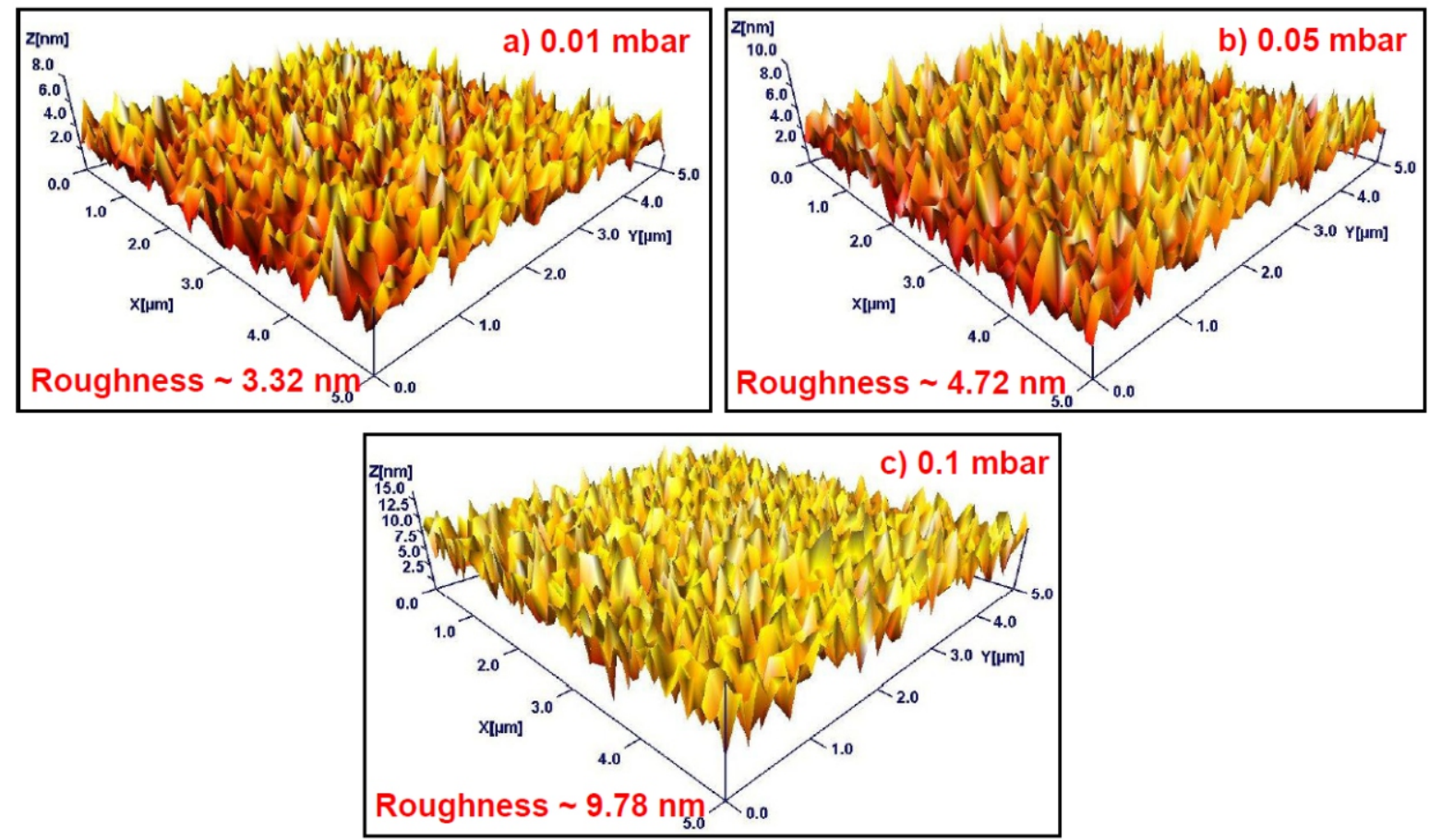

Fig. 4 3-D AFM $(5 \times 5 \mu \mathrm{m})$ images of Mo thin films at deposited at various working gas pressures a) $0.01 \mathrm{mbar}$ b) $0.05 \mathrm{mbar}$ and c) $0.1 \mathrm{mbar}$. 


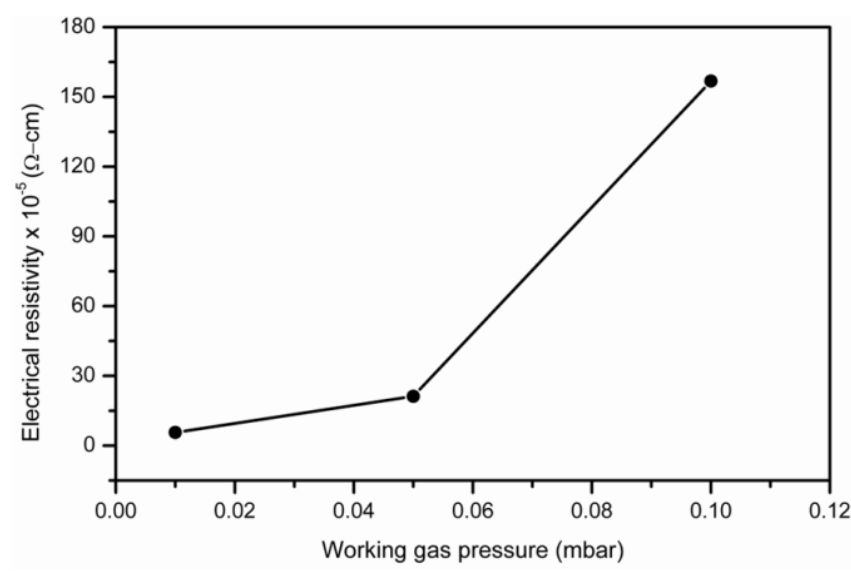

Fig. 6 Electrical resistivity of Mo films deposited at different working gas pressure.

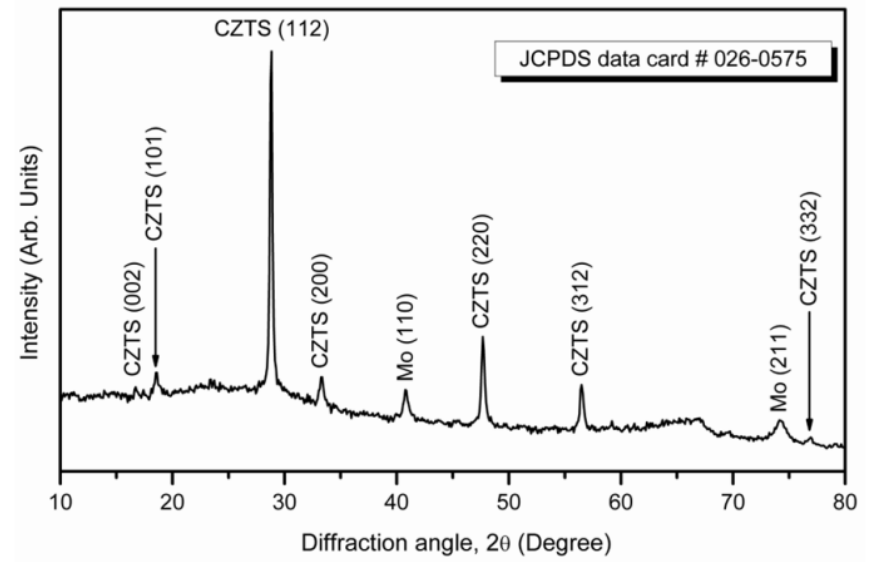

Fig. 7 XRD pattern of CZTS thin film deposited on Mo coated glass substrate and annealed at $475^{\circ} \mathrm{C}$ for 10 minutes in $\mathrm{Ar}+\mathrm{H}_{2} \mathrm{~S}$ atmosphere. minimize the series resistance of solar cell device. The electrical resistivity of Mo films was measured using Van der Pauw method (Ecopia HMS-3000 Hall Measurement System) at room temperature. Fig. 6 shows the variation of electrical resistivity of Mo thin films deposited at different working gas pressure. As seen from the figure, the electrical resistivity gradually increases from $5.67 \times 10^{-5} \Omega-\mathrm{cm}$ to $15.6 \times 10^{-4} \Omega-\mathrm{cm}$ when the working gas pressure increased from 0.01 mbar to 0.1 mbar [Fig. 6]. At higher working gas pressure, there is a reduction in kinetic energy of Mo thin films due to increased particle scattering. Hence, less dense films were formed. As a result, the electrical resistivity of Mo thin film increases. ${ }^{41}$ Scofield et al. ${ }^{17}$ reported that enhancement of porosity is responsible for increase in resistivity at higher gas pressures.

\section{Czts Thin Film Deposition}

The $\mathrm{Cu}_{2} \mathrm{ZnSnS}_{4}$ (CZTS) thin films were deposited on DC sputtered Mo thin films by electrochemical deposition (Potentiostat: Metrohm Autolab PGSTAT302N) at room temperature. The electrochemical deposition of CZTS thin films was carried out in a conventional three-electrode electrochemical cell assembly on Mo-thin film deposited at working gas pressure of 0.05 mbar. The Mo-coated glass substrate was used as the working electrode, a platinum electrode as an inert counter electrode and saturated calomel electrode (SCE) as a reference electrode. The electrolytic bath consists of $20 \mathrm{mM} \mathrm{CuSO}_{4}, 10 \mathrm{mM} \mathrm{ZnSO}, 20 \mathrm{mM}$ $\mathrm{SnSO}_{4}$ and $16 \mathrm{mM} \mathrm{Na}_{2} \mathrm{~S}_{2} \mathrm{O}_{3}$. The tri-sodium citrate $\left(\mathrm{Na}_{3} \mathrm{C}_{6} \mathrm{H}_{5} \mathrm{O}_{7}\right)$ was used as complexing agent in precursor solution. The $\mathrm{pH}$ of the electrolytic solution was 4.5-5.0. The Mo-coated glass substrates were cleaned ultrasonically in acetone, ethanol and double distilled water. The uniform and well adherent CZTS thin films were deposited at $-1.05 \mathrm{~V}$ vs SCE in potentiostatic mode at room temperature for $45 \mathrm{~min}$. After deposition, the films were rinsed in doubly distilled water. The deposited films were annealed at $475{ }^{\circ} \mathrm{C}$ for 10 minutes in $\mathrm{Ar}+\mathrm{H}_{2} \mathrm{~S}$ atmosphere and used for further the investigations.

The XRD pattern of annealed CZTS film deposited on Mo coated glass substrate is shown in Fig. 7. It is observed from figure that CZTS film have major diffraction peaks at $2 \theta \sim 28.77,33.28,47.00$ and 54.42. These diffraction peaks are well matched with those of standard data and identified to be due to reflections originated from (112), (200), (220) and (312) planes respectively of characteristic of kesterite crystal structure of CZTS (JCPDS card \# 26-0575). The strongest (intense) peak at $2 \theta \sim 28.77$ represents the preferential orientation along the (112)



Fig. 8 Raman spectra of CZTS thin film deposited on Mo coated glass substrate and annealed at $475{ }^{\circ} \mathrm{C}$ for 10 minutes in $\mathrm{Ar}+\mathrm{H}_{2} \mathrm{~S}$ atmosphere.

plane. The highly intense and sharpness of (112) peak indicate that the material has the high degree of crystallinity. No noticeable diffraction peaks due to secondary phases were observed in the diffraction pattern signifying formation of pure kesterite phase of CZTS. Existence of kesterite-CZTS is further confirmed by Raman spectroscopy.

The Raman spectrum of CZTS thin film deposited on Mo coated glass substrate and annealed at $475{ }^{\circ} \mathrm{C}$ for 10 minutes in $\mathrm{Ar}+\mathrm{H}_{2} \mathrm{~S}$ atmosphere in the range $100-600 \mathrm{~cm}^{-1}$ is shown in Fig. 8. As seen two major shoulders corresponding to the CZTS films were observed at 338 $\mathrm{cm}^{-1}$ and $288 \mathrm{~cm}^{-1}$. The strongest peak is located at $338 \mathrm{~cm}^{-1}$, is the main vibrational A1 symmetry mode from kesterite-CZTS phase. ${ }^{42}$ No additional Raman peaks were observed corresponding to various binary phases, suggesting that formation of the pure single phase of kesteriteCZTS film. The results are consistent with the results obtained from $\mathrm{XRD}$ analysis.

\section{Conclusions}

We have deposited Mo thin films having low resistivity and high adhesion by DC-magnetron sputtering for back contact electrode for electrochemical deposition of CZTS absorber layer. We have investigated the influence of the working gas pressure on structural, electrical, optical and morphological properties of Mo thin films 
deposited by DC-Magnetron sputtering. The enhancement in adhesion of Mo film on corning glass substrate has been observed with increase in working gas pressure which is tested by using Cross-hatch cut and Scotch tape adhesion test. The XRD analysis showed that as-deposited Mo films have preferred orientation in (110) direction. With increase in working gas pressure, decrease in crystallite size has been observed. Moreover, XRD analysis showed that the Mo films deposited at working gas pressure 0.01 mbar exhibit compressive strain while deposited at 0.05 mbar and above exhibit tensile strain. Enhancement in porosity of Mo films was observed with increase in working gas pressure and was investigated using FE-SEM analysis. Non-contact atomic force microscopy (NC-AFM) revealed that the average surface roughness of the films increases from $3.32 \mathrm{~nm}$ to $9.78 \mathrm{~nm}$ when working gas pressure increased from $0.01 \mathrm{mbar}$ to $0.1 \mathrm{mbar}$. Electrical properties carried out using Hall Effect measurements showed that the electrical resistivity of Mo films increases with increase in working gas pressure. Finally, kesterite-CZTS compound with no secondary phases has been revealed by XRD and Raman spectroscopy of electrodeposited CZTS.

\section{Acknowledgement}

Haribhau Borate is grateful to University Grant Commission (UGC), New Delhi for Teacher Fellowship under Faculty Improvement program (FIP) for college teachers. Ajinkya Bhorde thankful to Department of Science and Technology (DST), Government of India for INSPIRE Ph. D. fellowship. Ravindra waykar, Shruthi Nair and Subhash Pandharkar are thankful to the Ministry of New and Renewable Energy (MNRE), Government of India for the financial support under National Renewable Energy Fellowship (NREF) program. One of the authors Sandesh Jadkar is thankful to University Grants Commission (UPE program), New Delhi and Indo-French Centre for the Promotion of Advanced Research-CEFIPRA, Department of Science and Technology, New Delhi for special financial support.

\section{References}

1. M.A. Green, J. Mater. Sci.: Mater. Electron., 2007, 18, S15-S19.

2. C. Malerba, F. Biccari, C. L. A. Ricardo, M. Valentini, R. Chierchia, M. Müller, A. Santoni, E. Esposito, P. Mangiapane, P. Scardi and A. Mittiga, J. Alloys. Compd., 2014, 582, 528-534.

3. P. Jackson, D. Hariskos, R. Wuerz, W. Wischmann, and M. Powalla, Phys. Status Solidi RRL 8, 2014, 3, 219-222

4. K. Masuko, M. Shigematsu, T. Hashiguchi, D. Fujishima, M. Kai, N. Yoshimura, T. Yamaguchi, Y. Ichihashi, T. Mishima, N. Matsubara, T. Yamanishi, T. Takahama, M. Taguchi, E. Maruyama and S. Okamoto, IEEE journal of photovoltaics, 2014, 4(6), 1433-1435.

5. K. Zweibel, H.S. Ullal, and R.L. Mitchell, Proc. 21st IEEE Photovoltaic Specialists' Conf., 1990, IEEE, New York, 1990, 458, 458-466.

6. C. A. Cattley, C. Cheng, S. M. Fairclough, L. M. Droessler, N. P. Young, J. H. Warner, J. M. Smith, H. E. Assender and A. A. R. Watt, Chem. Commun., 2013, 49, 3745.

7. K. Tanaka, M. Kato and H. Uchiki, J. Alloys. Compd., 2014, 616, 492-497.

8. K. Ito and T. Nakazawaand, Jpn. J. Appl. Phys., 1988, 27, 2094-2097.

9. T. Tanaka, D. Kawasaki, M. Nishio, Q. Guo and H. Ogawa, Phys. Stat. Solidi (c), 2006, 3, 2844-2847.

10. W. Ki and H. W. Hillhouse, Adv. Energy Mater.,2011, 1, 732-735.
11. W. Wang, M. T. Winkler, O.Gunawan, T. Gokmen, T. K. Todorov, Y. Zhu and D. B. Mitzi, Adv. Energy Mater., 2014, 4, 1301465.

12. H. Ahn, D. Lee and Y. Um, Appl. Sci. Converg. Technol., 2017, 26, 11-15.

13. F. Z. Boutebakh, M. L. Zeggar, N. Attaf, M. S. Aida, N. Attaf and M. S. Aida, Optik, 2017, 144,180-190.

14. F. A. AbouElfotouh, L. L. Kazmerski, T. J. Coutts, R. J. Matson, S. E. Asher, A. J. Nelson and A. B.S. Franz, J. Vac. Sci. Technol. A, 1989, 7, 837-841.

15. K. Orgassa, H. W. Schock and J. H. Werner, Thin. Solid. Films., 2003, 431432, 387-391.

16. B. Ghosh, D. P. Chakraborty and M. J. Carter, Semicond. Sci. Technol., 1996, 11, 1358-1362.

17. J. H. Scofield, A. Duda, D. Albin, B.L. Ballard and P.K. Predecki, Thin Solid. Films., 1995, 260, 26-31.

18. S. A. Pethe, E. Takahashi, A. Kaul and N. G. Dhere, Sol. Energy Mater. Sol. Cells, 2012, 100, 1-5.

19. M. A. Martinez and C. Guillen, Surf. Coat. Technol., 1998, 110, 62-67.

20. G. Gordillo, F. Mesa and C. Calderon, J. Phys. 2006, 36, 982-985.

21. K. Kawabata and T. Tanaka, Mater.Sci. Eng., 1993, A163, 163-165.

22. M. A. Martınez and C. Guillen, J. Mater. Process. Technol., 2003, 143-144, 326-331

23. C. H. Huang, H. L. Cheng, W. E. Chang, M. Yi Huang andY. J. Chien, Semicond. Sci. Technol., 2012, 27, 115020 (9pp).

24. S. R. Rondiya, A. V. Rokade, A. A. Jadhavar, S. M. Pandharkar, R. R. Kulkarni, S. D. Karpe, K. D. Diwate and S. R. Jadkar, AIP Conference Proceedings, 2016, 1724, 020089.

25. S. M. Pandharkar, S. R. Rondiya , A. V. Rokade, B. B. Gabhale, H. M. Pathan and S. R. Jadkar, Front. Mater., 2018, 5(13),1-6.

26. B. Guo, Y. Wang, X. Zhu, M. Qin, D. Wan and F. Huang, COL, 2016, 14(4), 043101

27. S. J. Wang, X. Li and Z. H. Chen, Chin. Sci. Bull., 2009, 54, 2606-2609.

28. S. G. Malhotra, Z. U. Rek, S. M. Yalisove and J. C. Bilello, J. Vac. Sci. Technol. A, 1997, 15, 345-352.

29. M. Khan, M. Islam, A. Akram, Z. Qi and L. Li, Mater. Sci. Semicond. Process., 2014, 27, 343-351.

30. S. M. Deambrosis, E. Miorin, F. Montagner, V. Zin, M. Fabrizio, M. Sebastiani, F. Massimi and E. Bemporad, Surf. Coat. Technol. 2015, 266, $14-21$

31. Rointan F. Bunshah, Materials Science and Process Technology Series, $2^{\text {nd }}$ Second edition (1994)

32. E. Gautron, M. Tomassini, L. Arzel and N. Barreau, Surf. Coat. Technol., 2012, 211, 29-32.

33. J. Ray, T. K. Chaudhuri and J. Optoelectron. Adv. Mater.,2015, 17, 634-639

34. R. V. Forest, E. Eser, B. E. McCandless, R. W. Birkmire and J. G. Chen, AIChE Journal, 2014, 60 (6), 2365-2372.

35. F. Jingxue, W. Zhao, W. Wei, Y. Ye, Z. Lin, W. Xin, H. Ruijiang, S. Hui and M. Z. Q. Chen, AIP Advances, 2016, 6, 115210-1.

36. B. Cullity and S. Stock, Elements of X-ray Diffraction, 3rd Edition, Princeton Hall (2001).

37. H. Khatri and S. Marsillac, J. Phys.: Condens. Matter, 2008, 20, 055206 (5pp).

38. W. Li, X. Yan, A. G. Aberle and S. Venkataraj, Jpn. J. Appl. Phys., 2015, 54, 08KC14-1-08KC14-6.

39. M. Jubault, L. Ribeaucourt, E. Chassaing, G. Renou, D. Lincot and F. Donsanti, Sol. Energy Mater. Sol. Cells, 2011, 95, S26-S31.

40. C. Hong, Z. Chuan Jun and C.Jun Hao, Sci. China Tech. Sci., 57(2014), 5, 947-952.

41. Z. H. Li, E.S. Cho and S. J. Kwon, Appl. Surf. Sci. 2011, 257, 9682-9688.

42. P. Fernandes, P. Salomé, A. Da Cunha and Thin Solid Films, 2009, 517, 2519-2523. 